\title{
Relationship between the Recurrent Laryngeal Nerve and the Inferior Thyroid Artery in the Togolese Subject: Surgical Anatomy Study from 227 Thyroidectomies
}

Bathokedeou Amana, ${ }^{1}$ Winga Foma, ${ }^{1}$ Essobozou Pegbessou, ${ }^{1}$ Tchin Darré, Essohanam Boko, ${ }^{1}$ Eyawèlohn Kpemissi ${ }^{1}$

Introduction

\section{ABSTRACT}

Identification of the recurrent laryngeal nerve during thyroid surgeries is recommended to preserve its functionl integrity. This study aims to determine the relationship between the recurrent laryngeal nerves and the inferior thyroid arteries during thyroidectomies, as well as any particularities and intraoperative complications.

\section{Materials and Methods}

Observational cross-sectional study of all culturally Togolese patients who underwent thyroidectomy with nerve dissection in the ENT department of Sylvanus Olympio University Hospital from 1 January 2013 to 30 June 2017, i.e. a period of 4 years 6 months

\section{$\underline{\text { Results }}$}

The sex ratio was 0.14 i.e., 7 women for 1 man and the average age of 41.82 years. Solitary nodules and multinodular goiters were the most operated lesions in $40.97 \%$ and $33.04 \%$, respectively, with a plunging character in 17 cases. We had 306 cases of nerve dissection but the recurrent laryngeal nerve could not be found in 1 case on the right. It was globally retro-arterial (under the trunk and under the branches of the inferior thyroid artery) in $75.08 \%$ of cases with prevalence of the truncal, pre arterial situation in $16.07 \%$ and inter-arterial in $3.28 \%$ cases. The nerve was non-recurrent (type II pathway) in 1 case on the right. There was no recurrence injury. Parathyroid devascularization (5 cases) was autotransplanted. The surgeon's experience did not have a significant impact on the occurrence of intraoperative complications $(p=0.24)$.

\section{Conclusion}

This observational cross-sectional anatomical-surgical study supports the existing data on the relationships between the recurrent laryngeal nerve and the inferior thyroid artery by confirming their variability. Nevertheless, it was marked by the predominance of the retro arterial truncal situation of the nerve unlike the literature that most often reports a situation of the nerve under the arterial branches.

Kevwords

Inferior Thyroid Artery; Recurrent Laryngeal Nerve; Thyroidectomy; Goiter; Togo

$\mathrm{R}$ ecurrent injuries are very dreaded lesions during thyroidectomies because of the dysphonia or dyspnea they cause, wherein dyspnea may be life-threatening in case of bilateral damage. Recurrent paralysis constitutes, with hypocalcemia, the most frequent immediate postoperative complications of thyroidectomies due to the anatomic relationships of the gland with the recurrent laryngeal nerves (RLN) or lower laryngeal nerves and parathyroids. ${ }^{1,2}$ Serious complications after thyroidectomy such as compressive hematoma and acute dyspnea by bilateral paralysis in closure have become rare, thus bringing to the fore lesions that were previously considered minor
1 - Université de Lomé, Togo
Corresponding author:
Dr Winga Foma
email: adrienfoma@yahoo.fr 
complications. Already in the sixth century, in the history of thyroidectomy, postoperative dysphonia by recurrent laryngeal nerve injury were recognised. ${ }^{3}$ Responsibility for recurrent paralyses in several deaths after the first thyroidectomies promptly led to changes in the surgical technique by identifying the nerves intraoperatively or performing an intracapsular dissection, with some success. Over time, the anatomical and functional preservation of RLN has become the gold standard of thyroid surgery. Various artifices have been described but it seems that the essential rule is the respect of a careful, rigorous and standardized surgical technique including RLN identification. ${ }^{2,4}$ Nerve tracing techniques have varied in recent years, from visual identification, through injection of blue dye in the inferior thyroid artery (ITA) to neuromonitoring. All in all, in practice, RLN tracking is guided by that of the ITAs. In sub-Saharan Africa, visual identification is the preferred technique of locating RLN as evident from the studies of Koumaré et al in Mali ${ }^{5}$ and Ngo nyeki et al in Cameroon and Gabon. ${ }^{6}$ Since thyroid surgery is one of the most frequent in otolaryngology (ENT) ${ }^{7}$ and because of the effectiveness of the training of ENT specialists for four years now in Togo, it seemed appropriate to carry out this study whose general objective was to have data facilitating the identification of RLN in the Togolese subject.

\section{Materials and Methods}

\section{Framework, population, type and period of study:}

Our study was conducted as part of the ENT and cervicomaxillo-facial (CMF) surgery department of Sylvanus Olympio University Hospital (CHU S.O.) in Lomé. The lack of neuromonitoring device in the operating room of the said service should be noted. It was a cross-sectional observational study of all culturally Togolese patients who underwent thyroidectomy with dissection of RLN in the ENT and CMF Surgery department from January 1st, 2013 to June 30th 2017, i.e., a period of 04 years 6 months. Depending on the procedure, it could be one or both nerves at risk. A consent was signed by the patient before any thyroid surgery in our practice and inclusion in the study.

\section{Selection criteria:}

Included in our study were all patients who underwent thyroidectomy with RLN dissection in the department during the study period. Excluded from the study population were cases of surgical revision imposed by the malignant nature of the operated lesion, patients with a history of thyroidectomy, non-culturally Togolese patients (cultural nationality was selected based on the names borne, spoken language and verbal confirmation by the patient). We did not include in our study the cases of Isthmectomy alone.

\section{Parameters studied:}

We were interested in the demographics, the operated thyroid injury, the surgical procedure performed, the intraoperative findings and the relationship between the ITA and the RLN.

\section{Analysis and data processing:}

The data was captured and analyzed using the Epi-Info 7 Software and the results were formatted using Excel 2013. The frequency comparison of the categorical variables was done using the Pearson's chi-square test considering its conditions of validity and realization. The decisions were taken with a risk $\alpha$ of $5 \%$.

\section{Results}

\section{General aspects:}

From January 1, 2013 to June 31, 2017, for a period of 04 years 6 months, 281 thyroidectomies were performed. Of these thyroidectomies, 227 (80.78\%) were selected for this study, based on the selection criteria. Three hundred six nerve dissections were performed including 148 unilateral and 79 bilateral. The female sex was represented in 199 cases $(87.67 \%)$ and the male sex in 28 cases $(12.33 \%)$. The sex ratio was 0.14 i.e., 1 man for 7 women. The average age was 41.82 years with a standard deviation of 13.58 years and extremes of 12 and 83 years. The age group of 30 to 45 years was the most represented with 94 cases $(41.41 \%)$. In 160 cases $(70.48 \%)$, the intervention was performed by an experienced surgeon (ENT specialist and head and neck 
surgeon) and in $29.52 \%$ of cases by a specializing doctor alone or under the supervision of a specialist circulating (observer).

Intraoperative findings and surgical aspects:

The nature of the thyroid lesion, determined preoperatively based on clinical and paraclinical examinations, was clarified intraoperatively. Tissue nodules and euthyroid multinodular goiters were the most common lesions with 93 cases $(40.97 \%)$ and 75 cases (33.04\%), respectively. A peculiar aspect of the gland was noted in 35 cases $(15.42 \%)$ dominated by the plunging character with 17 cases. Other features were: haemorrhagic gland (11 cases), tumor infiltration of surrounding tissues (3 cases), hypertrophy of a parathyroid ( 2 cases) and tracheomalacia ( 2 cases). Relationship between the recurrent laryngeal nerve and the inferior thyroid artery (Figs. 1 and 2)

We had 306 cases of nerve dissection distributed 154 on the right and 152 on the left. The nerve could not be found on the right in 1 case; the procedure then being continued by dissection in contact with the gland until excision. The RLN was retro-arterial in 200 out of 305 nerves $(65.57 \%)$ distributed between the left side (101 cases) and the right side (99 cases); it was globally retroarterial (under the trunk and under the branches of the ITA) in 112 cases on the right on 153 nerves $(73.20 \%)$ and 117 on the left $(76.97 \%)$. RLN was globally prearterial in 49 cases $(16.07 \%)$ and inter-arterial in 10 cases $(3.28 \%)$. In 6 cases, the ITA was not found, 4 on the left and 2 on the right. The nerve was non-recurrent (Type II Pathway) in 1 case (right) and no further exploration to identify an associated asymptomatic malformation was made. RLN position variations with respect to genderspecific ITA were not statistically significant (Table I); those of the RLN compared to the ITA according to the diagnosis (Tables II and III) did not note a statistically significant difference on the right $(p=0.74)$ or on the left $(\mathrm{p}=0.56)$.

Table I: RLN position variations in relation to ITA according to gender

\begin{tabular}{|c|c|c|c|}
\hline & \multicolumn{2}{|c|}{ NUMBER } & \multirow{2}{*}{ P-VALUE } \\
\hline & FEMALE & MALE & \\
\hline Right retroarterial (crossing under the trunk) & 85 & 14 & 0.6 \\
\hline Left retroarterial & 88 & 13 & 0.99 \\
\hline Right prearterial (crossing over the trunk) & 20 & 2 & 0.88 \\
\hline Left prearterial & 21 & 3 & 0.76 \\
\hline Right interarterial (between branches) & 8 & $\mathbf{0}$ & 0.59 \\
\hline Left interarterial & 2 & $\mathbf{0}$ & 0.58 \\
\hline Under the branches on the right & 10 & 3 & 0.44 \\
\hline Under the branches on the left & 14 & 2 & 0.71 \\
\hline On the right branches & 2 & $\mathbf{0}$ & 0.58 \\
\hline On the branches on the left & 1 & $\mathbf{0}$ & 0.25 \\
\hline Parallel inside on the right & 6 & $\mathbf{0}$ & 0.76 \\
\hline Parallel inside on the left & 3 & 1 & 0.99 \\
\hline Other positions & 7 & 2 & 0.68 \\
\hline
\end{tabular}




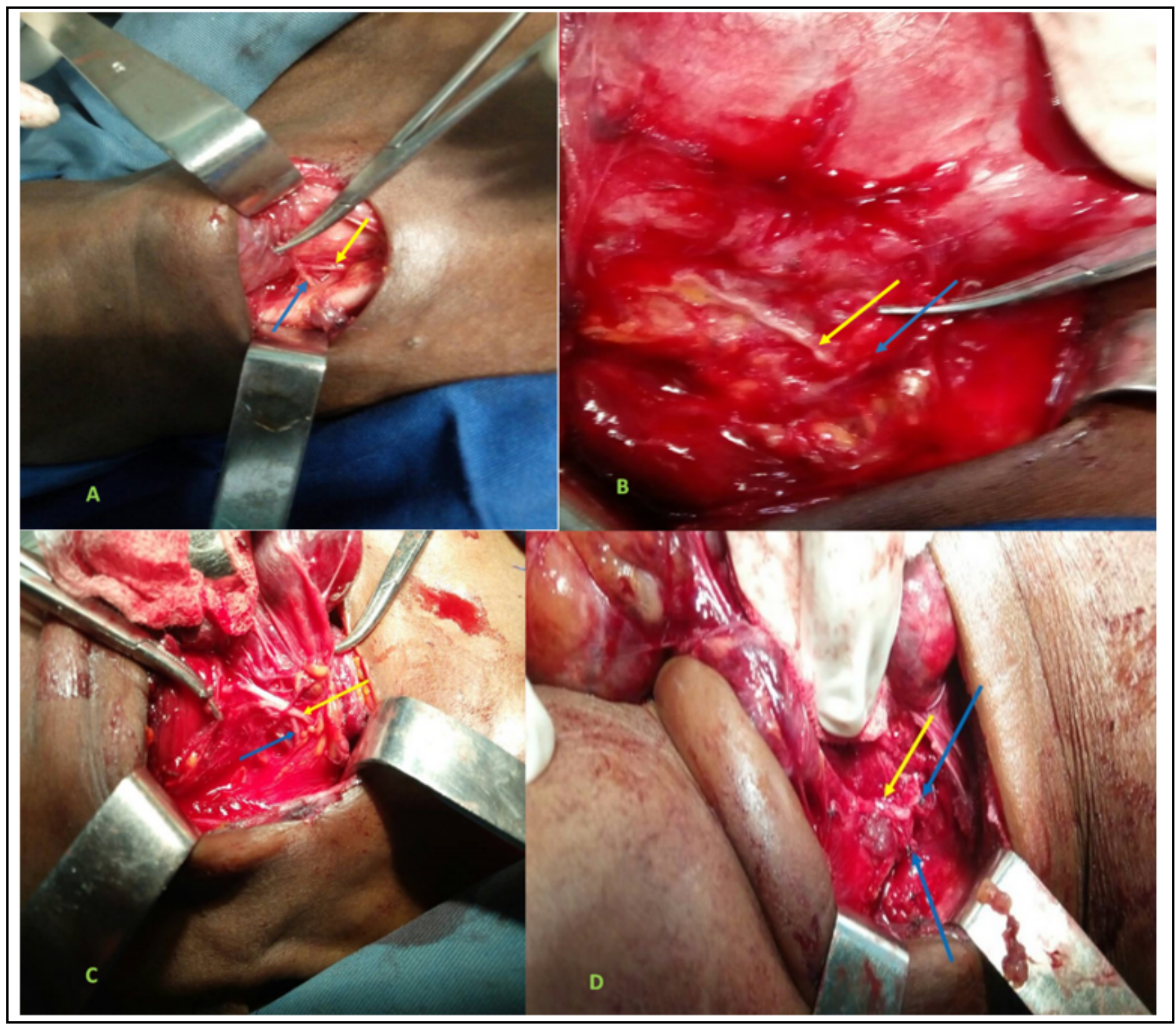

Fig. 1. Some relationships between the right RLN (yellow arrow) and the right ITA (blue arrow): retro arterial nerve (A and B); pre-arterial nerve (C); inter-arterial nerve (D) with ligated arterial branches.

\section{Intraoperative complications}

They were present in 8 cases (3.52\%) including 1 case of sacrifice of the left RLN infiltrated by the tumor lesion. There has not been, strictly speaking, any recurrent nerve injury. Inadvertent parathyroid devascularization was noted in 5 patients, concerned the left lower parathyroid (3 cases), the right lower parathyroid (1 case) and the two right parathyroid ones in 1 case. Parathyroid auto transplantation was performed in these cases. Other complications were the tracheal rupture and a wound in the thoracic duct. Lymphatic leak occurred during a bilateral neck dissection (left radical and right functional) and was associated with total thyroidectomy. The tracheal rupture was made from the 2 nd to the 4th tracheal ring at the junction of the cartilaginous (anterolateral) and non-cartilaginous (posterior) parts on the left side of the exterior of the mass of thyroid. The surgeon's experience did not have a significant impact on the occurrence of complications in this study $(\mathrm{p}=0.24)$. 


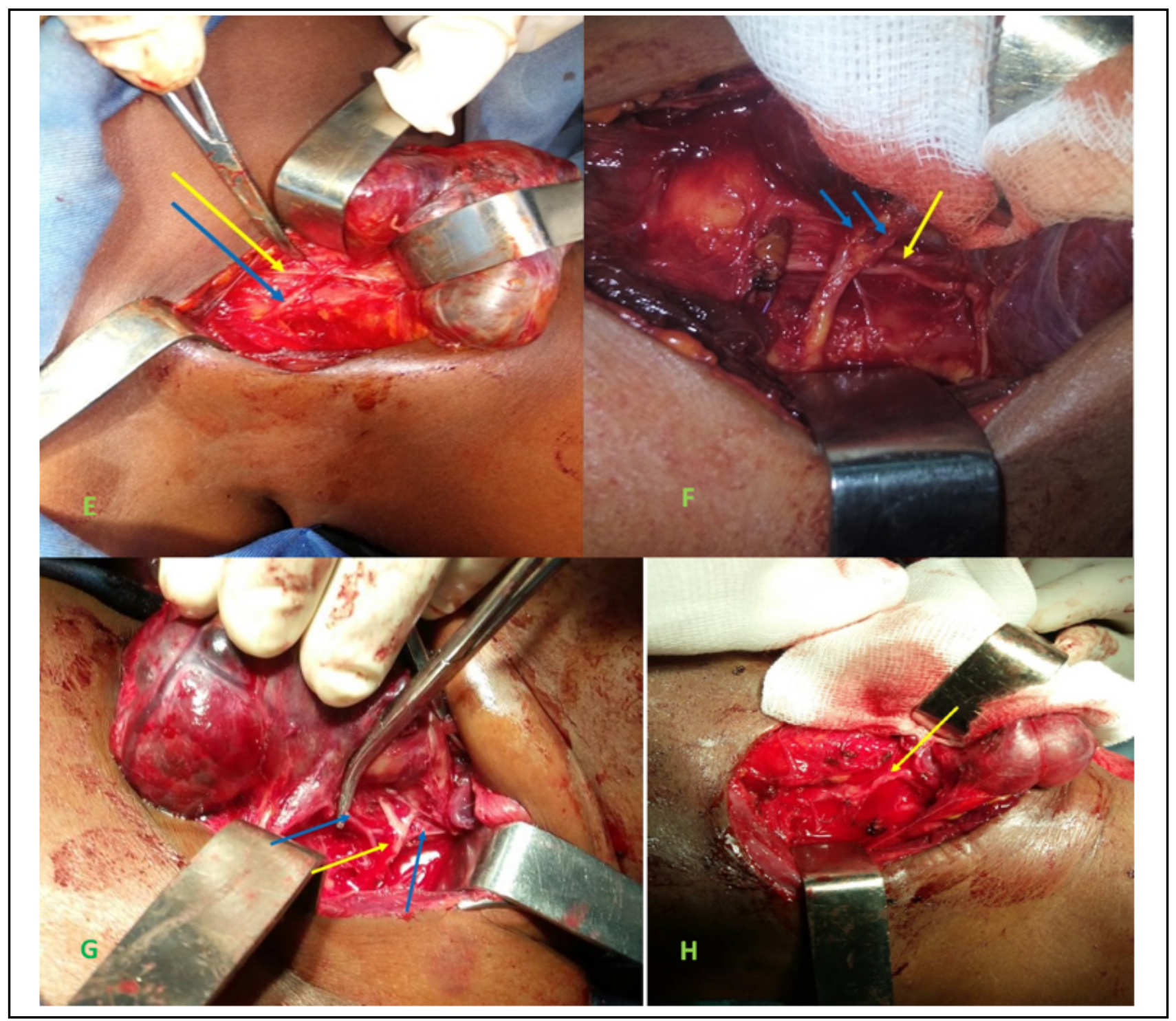

Fig. 2. Some relationships between the left RLN (yellow arrow) and the left ITA (blue arrow): retro arterial nerve (E); nerve under the arterial branches $(F)$; inter-arterial nerve $(G)$; ITA absent $(H)$.

\section{Discussion}

Our study was an observational study on the relationship between the recurrent laryngeal nerve and the inferior thyroid artery in the Togolese subject. This study was made possible by the adhesion of all the surgeons to provide, as far as possible, the necessary information, thus allowing homogeneity in the collection of data. Indeed, although the search for RLN during thyroidectomy has been systematic in our practice for several years, the precision of the anatomico-surgical data on the nerve began with the present study.

Cases of surgical revision imposed by the malignant nature of the operated lesion and patients with a history of thyroidectomy were excluded from the study because of the anatomical changes that would have already led to an earlier exploration of the thyroid compartment. Also, postoperative inflammatory changes make dissections 
Table II: Position variations of the right RLN relative to the ITA according to the diagnosis.

\begin{tabular}{|c|c|c|c|c|c|c|}
\hline & $\begin{array}{c}\text { RETRO } \\
\text { ARTERIAL }\end{array}$ & $\begin{array}{c}\text { PRE } \\
\text { ARTERIAL }\end{array}$ & $\begin{array}{c}\text { UNDER } \\
\text { BRANCHES }\end{array}$ & $\begin{array}{c}\text { INTER } \\
\text { ARTERIAL }\end{array}$ & OTHER & TOTAL \\
\hline Multinodular goitre & 39 & 9 & 9 & 3 & 4 & 64 \\
\hline $\begin{array}{c}\text { Basedow multinodular } \\
\text { goitre }\end{array}$ & 3 & 1 & $\mathbf{0}$ & $\mathbf{0}$ & $\mathbf{0}$ & 4 \\
\hline Simple goitre & 4 & 1 & $\mathbf{0}$ & $\mathbf{0}$ & $\mathbf{0}$ & 5 \\
\hline Basedow disease & 21 & 2 & $\mathbf{0}$ & 1 & 1 & 25 \\
\hline Cystic nodule & 2 & $\mathbf{0}$ & $\mathbf{0}$ & $\mathbf{0}$ & 1 & 3 \\
\hline Mixed nodule & 2 & 2 & 2 & 1 & 1 & 8 \\
\hline Tissue nodule & 26 & 7 & 2 & 3 & 5 & 43 \\
\hline $\begin{array}{l}\text { Malignant neoplasm of } \\
\text { the thyroid body }\end{array}$ & 2 & $\mathbf{0}$ & $\mathbf{0}$ & $\mathbf{0}$ & $\mathbf{0}$ & 2 \\
\hline Total & 99 & 22 & 13 & 8 & 12 & 154 \\
\hline
\end{tabular}

difficult, thus promoting the risk of nerve damage as reported by some authors. ${ }^{2,8,9}$

We considered cultural or sociological nationality based on the name borne, the language spoken by the patients and the verbal confirmation to include them as Togolese subjects. This procedure avoids consideration of legal or political nationality which, although legal, could include non-Togolese subjects who may have different anatomical particularities. Isthmectomy cases were not included in this study because it is an RLN-free intervention. The didactic aim of this study, the general objective of which was to have data facilitating the identification of RLN in the Togolese subject, explains the methodology applied in this work.

Several RLN positions have been reported, but overall, three types of positions come up frequently: ${ }^{10,11}$

- Globally retro-arterial nerve (under the trunk or branches of the ITA)

- Globally pre-arterial nerve

- Inter-arterial nerve

We summarize in Table IV some comparative aspects between our series and other anatomico-surgical studies (excluding cadaveric dissections) carried out on a given 


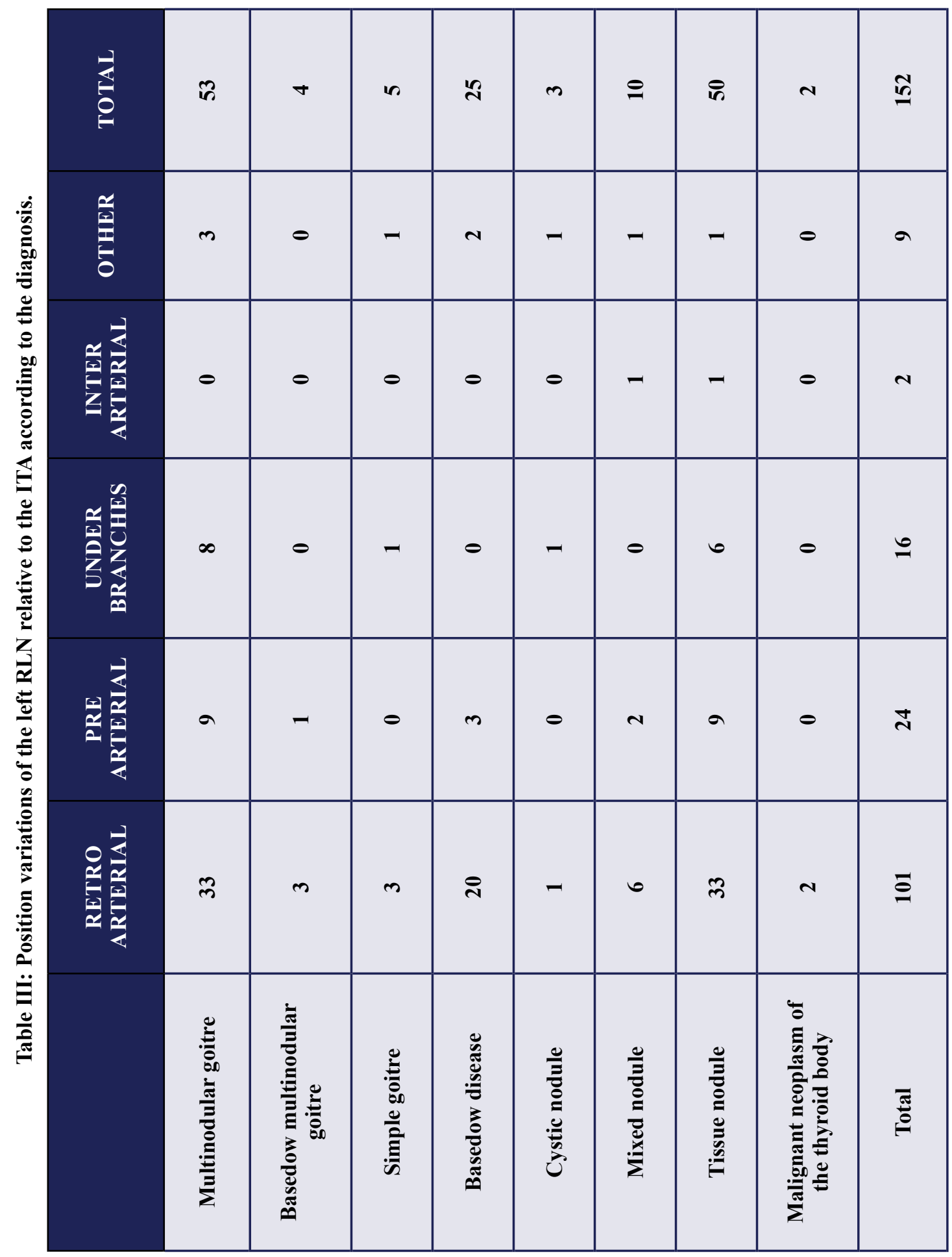




\begin{tabular}{|c|c|c|c|c|c|c|c|}
\hline 前 & 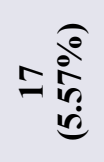 & $\theta$ & $\frac{\dot{b}_{0}^{\circ}}{\dot{n}}$ & $=\frac{\stackrel{\Im}{\stackrel{i}{+}}}{\stackrel{d}{d}}$ & 0 & 0 & 0 \\
\hline$\frac{\alpha}{\underline{x}}$ & $=\frac{\stackrel{0}{\stackrel{0}{0}}}{\stackrel{0}{0}}$ & 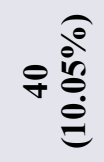 & 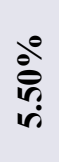 & a & 0 & 0 & $\therefore \frac{\sqrt[\partial]{8}}{\stackrel{d}{d ~}}$ \\
\hline & 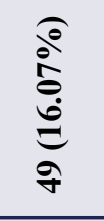 & 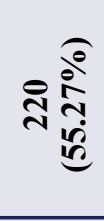 & $\frac{\partial}{i}$ & ' & हैं & 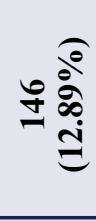 & 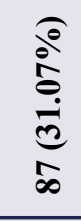 \\
\hline 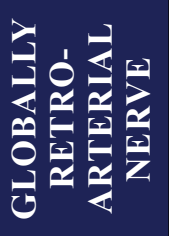 & 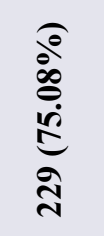 & 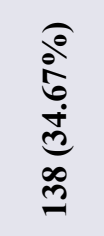 & $\frac{\stackrel{0}{\oplus}}{\stackrel{+}{\infty}}$ & 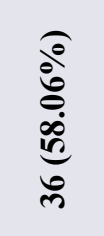 & 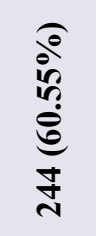 & 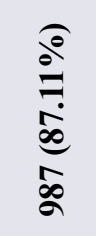 & 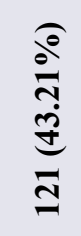 \\
\hline 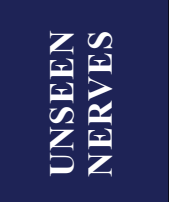 & - & $\stackrel{\infty}{=}$ & $\theta$ & 0 & 0 & in & ले \\
\hline 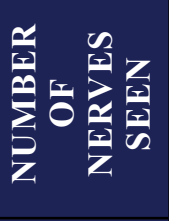 & ల్ల & ले & జ్ & $\widetilde{\sigma}$ & $\tilde{q}$ & $\stackrel{m}{=}$ & $\underset{\mathbb{N}}{\stackrel{\sim}{~}}$ \\
\hline 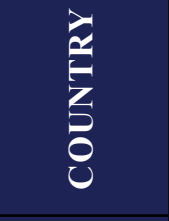 & مُ & 竞 & $\frac{\lambda}{\sqrt{\pi}}$ & ڤี & 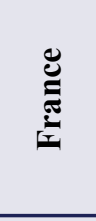 & 氺 & $\frac{2}{\pi}$ \\
\hline 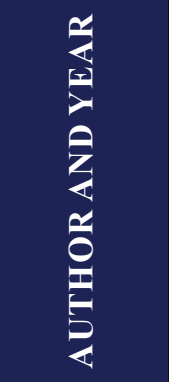 & 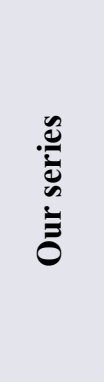 & 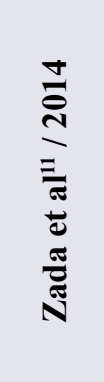 & 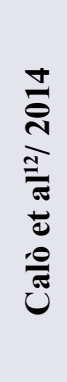 & 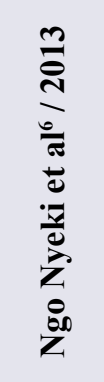 & 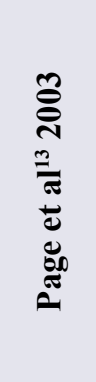 & 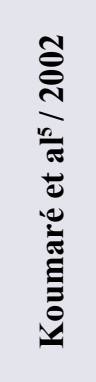 & 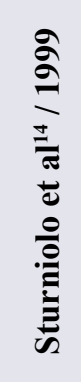 \\
\hline
\end{tabular}


population in order to identify any peculiarities.

This comparison confirms the variability of the RLN position relative to the ITA but a relative predominance of the retro-arterial position. The remarkable peculiarity is the low frequency of reports with arterial branches in our series compared to what is reported in the literature. ${ }^{7,15}$ This brings us to the possibility of anatomical changes by the thyroid masses that are often bulky in our part of the world because of the delay in consultation, then pushing the retro and pre-arterial nerve towards the truncular part of the artery. The goiter often leads to much less predictable changes in the nerve situation, especially in cases of inferior polar nodules plunging into the upper orifice of the thorax. ${ }^{4}$

The visual identification of RLNs from ITAs allowed the identification of almost all nerves in our context thus confirming the use of this report as a method of choice in locating RLN alongside that using Zuckerkandl's tubercle (ZT), Berry's ligament and the tracheoesophageal groove. Classically, the RLN can be identified intraoperatively as a side of Simon's triangle which is formed by the common carotid posteriorly, the RLN anteriorly and the ITA as the base. ${ }^{7}$ These other methods have limitations in the search for RLNs.

The use of ZT in locating is limited by its inconsistency and confusion in multinodular goiters with supracentimetric nodules. The morphometric classification of ZT proposed by Pelizzo et al is as follows: ${ }^{16}$

- Grades 0 and 1, the tuber is practically undetectable or reduced to a slight glandular mound;

- Grade 2 corresponds to a tuber whose large diameter is less than $1 \mathrm{~cm}$;

- Grade 3 corresponds to a tuber of more than $1 \mathrm{~cm}$.

It is therefore clear that only grades 2 and 3 of ZT assist in locating RLNs. In Togo, in a series of 48 patients, James et al did not find ZT in more than half of patients $(56.21 \%) .{ }^{17}$

The use of the Berry ligament, which is a thickening of the Gruber's thyroid tracheal ligament attaching the posteromedial edge of the thyroid gland to the cricoid cartilage and to the 1st and 2nd tracheal rings most often encounters bleeding, characteristic of this area with a risk of injury to the nerve at its point of entry into the larynx. The lower laryngeal nerve is less than
$3 \mathrm{~mm}$ from this ligament generally, runs behind it and must be identified before cutting the ligament. The dense and vascular nature of the Berry's ligament, the multiple branches of RLN that may be present at this level, the presence of nerve curvature at its laryngeal entry point and the close relationship of thyroid tissue to this ligament makes this region the most difficult area of nerve dissection during thyroidectomy. ${ }^{7,18}$

The tracheoesophageal groove is easily usable in locating the left and right RLN because of the deviation of the esophagus to the left and the generally vertical path of the nerve in the tracheoesophageal groove.

The case of right RLN not seen in our series might be a very small nerve or unusual position; the excision of the lesion having been made by strict dissection upon contact. Cases of difficult identification of RLNs as in surgical revisions may benefit from neuromonitoring, ${ }^{12,19,20}$ or staining methods. ${ }^{21}$ There are limitations to these other means of identification:

- RLN monitoring is essentially a nerve stimulation technique whose major interest is bilateral thyroid or parathyroid surgery and revision surgeries. It is a powerful tool that is not for nerve identification but makes it possible to evaluate the prognosis of its future function by the response to its intraoperative stimulation. ${ }^{19}$ Apart from the fact that its impact on the occurrence of definitive laryngeal paralysis is not really proven, ${ }^{12,20}$ its use comes up against the problem of the relatively high cost ranging from 15000 to 20000 Euro. 22,23

- The staining methods (patent blue, isosulfan blue, methylene blue), far from being common methods of detection, occasionally meet the phenomena of perioperative or even anaphylactic allergic reactions. ${ }^{24}$

The nerve was non-recurrent (type II path) on the right in one case of our series. This rare anomaly is related to an abnormal development of the aortic arches and is constantly accompanied by a subclavian retrooesophageal artery (arteria lusoria) sometimes causing dysphagia. This dysphagia was not reported in our case and did not require exploration in this direction.

The unilateral absence of ITA in 6 cases of our series has not been a trap for the discovery of the RLN in our practice; the discovery of the nerve having been made 
by dissecting the presumed area of the artery. Authors recognize that ITA agenesis facilitates the exteriorization of the thyroid lobe and the search for the nerve without risk of traction on the latter ${ }^{4}$ but may compromise the vascularization of parathyroid glands in case of reckless dissection. ${ }^{25}$

The surgeon's experience did not have a significant impact on the occurrence of complications in this study $(p=0.24)$. Studies do not agree on this. Some do not find a difference in recurrent morbidity according to the expertise of the surgeon while others show very clearly a lower rate of recurrent paralysis when the intervention is performed by experienced surgeons. For Trésallet et $\mathrm{al}^{2}{ }^{2}$ what is remarkable in the different studies is the paramount importance of the general experience of the centre where the patients are operated; young employees being able to achieve results close to those of seniors if they follow carefully and rigorously accurate and evaluated operating protocols.

\section{Conclusion}

This observational cross-sectional anatomico-surgical study supports the existing data on the relationship between the RLN and the ITA by confirming their variability. Nevertheless, it was marked by the predominance of the RLN truncular arterial situation unlike the literature that most often reports a situation of the nerve under the arterial branches of the ITA. This situation suggests the possibility of anatomical changes related to the usually large thyroid masses in our practice setting. The high rate of nerve discovery and the virtual absence of anatomical nerve damage confirm the prominent place occupied by the visual identification of RLN from ITAs in thyroid surgery. The anatomical integrity of the RLN is not a guarantee of its functional integrity, because of the possibility of transient paralysis, intraoperative monitoring of RLN could help improve the prognosis of future nerve function.

Funding source: This research received no specific grant from any funding agency, commercial or not-forprofit sectors.

Conflict of interest: none

\section{References}

1. Christou N, Mathonnet M. Complications after total thyroidectomy. J Visc Surg. 2013. http://dx.doi.org/10.1016/j. jviscsurg.2013.04.003

2. Trésallet C, Chigot J-P, Menegaux F. Comment prévenir la morbidité récurrentielle en chirurgie thyroïdienne? Ann Chir. 2006; 13:149-53

3. Giddings AEB. The history of thyroidectomy. J R Soc Med. 1998; 91:(Suppl. 33):3-6

4. Lubrano D, Levy-Chazal N, Araya Y, Avisse C. la recherche du nerf laryngé inférieur ou récurrent lors d'une lobectomie thyroïdienne. Ann Chir. 2002;127:68-72

5. Koumaré AK, Ongoiba N, Sissoko F, Berete S, Traoré Diop AK, Sidibé Y, et al. Nerf Laryngé Inférieur : anatomie et lésions opératoires. e-mémoires de l'Académie Nationale de Chirurgie 2002;1(2):8-11

6. Ngo nyeki A, EveheVokwely J, Miloundja J, Njock L, Bengono Toure G. Repérage des nerfs laryngés inférieurs dans la chirurgie thyroïdienne en Afrique Centrale : étude prospective multicentrique basée sur 62 dissections. Ann Otolaryngol Chir Cervicofac. 2013 ; 130(4 Suppl) : A161

7. Panieri E, Fagan J. Thyroidectomy. Open access atlas of otolaryngology, head \& neck operative surgery 2014. https:// vula.uct.ac.za/access/content/group/ba5fb1bd-be95-48e581be-586fbaeba29d/Thyroidectomy.pdf

8. Pelizzo MR. Difficult thyroidectomies. G Chir. 2015; 36 (2):4956

9. El Malki HO, Mohsine R, El Mazouz S, Ait Taleb K, Chefchaouni $\mathrm{MC}$, Oulbacha $\mathrm{S}$, et al. Les réinterventions après thyroïdectomie pour goître. Ann Endocrinol. 2002; 63(3):193-6

10. Campos BA, Henriques PRF. Relationship between the recurrent laryngeal nerve and the inferior thyroid artery: a study in corpses. Rev Hosp Clín Fac Med S Paulo 2000; 55(6):195200

11. Zada B, Anwar K, Malik SA, Niamatullah, Khan N, Salam F. Anatomical relationship between recurrent laryngeal nerve and inferior thyroid artery in thyroidectomy patients. J Ayub Med Coll Abbottabad 2014; 26(3):380-3

12. Calò PG, Pisano G, Medas F, Pittau MR, Gordini L, Demontis $\mathrm{R}$, et al. Identification alone versus intraoperative neuromonitoring of the recurrent laryngeal nerve during thyroid surgery: experience of 2034 consecutive patients. J Otolaryngol Head Neck Surg. 2014 43:16

13. Page C, Foulon P, Strunski V. The inferior laryngeal nerve: surgical and anatomic considerations. Report of 251 thyroidectomies. Surg Radiol Anat. 2003 ; https://doi. org/10.1007/s00276-003-0129-7

14. Sturniolo G, D'Alia C, Tonante A, Gagliano E, Taranto F, Lo Schiavo MG. The recurrent laryngeal nerve related to thyroid surgery. Am J Surg. 1999;177(6):485-8 
15. Tran Ba Huy P, Kania R. thyrö̈dectomie. EMC (Elsevier SAS, Paris), 46-460, 2004

16. Pelizzo MR, Toniato A, Gemo G. Zuckerkandl tubercle: an arrow pointing to the recurrent laryngeal nerve (constant anatomical landmark). J Am Coll Surg. 1998;187:333-6

17. James YE, Doleagbenou A, Kassegne I, Biramah BT, Keke K, Dosseh ED, et al. Le tubercule de Zuckerkandl : incidence et rapport avec le nerf laryngé inférieur. Morphol. 2014; 98:171-5

18. Lalruatkimi K, Balasubramanian T. Recurrent Laryngeal Nerve: Anatomical perspective. Online J Otolaryngol. 2015; 5(5):30-6

19. Périé S. Faut-il "monitorer" le nerf récurrent en chirurgie thyroïdienne ? Moyens et intérêt du monitoring du nerf récurrent. La Lettre d'ORL et de chirurgie cervico-faciale 2009 ; (317):33-4

20. Rulli F, Ambrogi V, Dionigi G, Amirhassankhani S, Mineo TC, Ottaviani F, et al. Méta-analysis of recurrent laryngeal nerve injury in thyroid surgery with or without intraoperatice nerve monitoring. Acta Otorhinolaryngol Ital. 2014; 34:223-9
21. Hepgul G, Kucukyilmaz M, Koc O, Duzkoylu Y, Sari YS, Erbil Y. The Identification of recurrent Laryngeal nerve by Injection of Blue Dye into the Inferior Thyroid Artery in Elusive Locations. J thyroid Res. 2013, http://dx.doi.org/10.1155/2013/539274

22. Dionigi G, Bacuzzi A, Boni L, Rausei S, Rovera F, Dionigi R. Visualization versus neuromonitoring of recurrent laryngeal nerves during thyroidectomy: what about the costs? World J Surg. 2012, 36:748-54

23. Loch-Wilkinson TJ, Stalberg PL, Sidhu SB, Sywak MS, Wilkinson JF, Delbridge LW. Nerve stimulation in thyroid surgery: is it really useful? ANZ J Surg. 2007;77:377-80

24. Langner-Viviani F, Chappuis S, Bergmann MM, Ribi C. Anaphylaxie aux colorants bleus. Rev Med Suisse 2014;10:87680

25. Montagne S, Brunaud L, Bresler L, Ayav A, Tortuyaux JM, Boissel P. Comment prévenir la morbidité chirurgicale de la thyroïdectomie totale pour goitre multinodulaire euthyroïdien ? Ann Chir. 2002; 127:449-55. 